\title{
Groei van zelf ervaren klinische competentie in de huis- artsopleiding en factoren die daarop van invloed zijn*
}

\author{
A.W.M. Kramer, P. Zuithoff, J.J.M. Jansen, L.H.C. Tan, R.P.T.M. Grol, C.P.M. van der Vleuten
}

\section{Samenvatting}

Inleiding: Doel van het onderzoek was na te gaan in hoeverre de driejarige vervolgopleiding tot huisarts bijdraagt aan de klinische competentie zoals die door aios zelf ervaren wordt. Daarnaast onderzochten we of we een relatie konden vinden tussen de groei van zelf ervaren competentie en verschillende achtergrondvariabelen.

Methode: We vroegen de aios die de huisartsopleiding volgden van 1995 tot 1998, om aan het begin en einde van de opleiding een lijst in te vullen waarin ze gevraagd werd een inschatting te maken van hun kennis, klinische vaardigheden en consultvoeringsvaardigheden. We verzamelden informatie over achtergrondvariabelen, waarvan wij vermoedden dat ze van invloed kunnen zijn op zelf ervaren competentie. Dit waren: leeftijd, geslacht, voorafgaande medische ervaring, de moeite die iemand doet voor haar/zijn opleiding, inzicht in zwakke en sterke gebieden van klinische competentie en objectief gemeten kennis- en vaardighedenniveau's.

Resultaten: 127 van de 190 aios vulden beide vragenlijsten in. We vonden een statistisch significante groei van zelf ervaren klinische competentie. Zelf ervaren consultvoeringsvaardigheden namen meer toe dan zelf ervaren kennis en klinische vaardigheden. De hierboven genoemde achtergrondvariabelen hadden geen enkele invloed op de groei.

Discussie en conclusie: Dit onderzoek heeft aangetoond dat een driejarige vervolgopleiding tot huisarts bijdraagt aan het eigen gevoel van klinische competentie. Echter, we weten nog steeds niet hoe deze bijdrage te verklaren is. Verder onderzoek naar het theoretisch concept van zelfevaluatie in het medisch onderwijs en naar factoren die bijdragen aan het eigen gevoel van competentie is dringend nodig. Dit is des te meer actueel bij een zelf gestuurde, competentiegerichte opleiding. (Kramer AWM, Zuithoff P, Jansen JJM, Tan LHC, Grol RPTM, Vleuten CPM van der. Groei van zelf ervaren klinische competentie in de huisartsopleiding en factoren die daarop van invloed zijn. Tijdschrift voor Medisch Onderwijs 2006;25(3): 134-142.)

\section{Inleiding}

De waarde van zelfevaluatie van klinische competentie als onderdeel van het individuele leerproces van medisch studenten, artsen in opleiding en praktiserende artsen is onmiskenbaar. ${ }^{1-2}$ Veel auteurs benadrukken het belang ervan voor levenslang leren en professionele autonomie. ${ }^{3-7}$
Echter, de waarde van zelfevaluatie ten behoeve van toetsing is minder duidelijk. ${ }^{1-2} 8$ De validiteit en nauwkeurigheid voor dit doel zijn uitgebreid onderzocht in het medisch onderwijs. Hoewel het design van de onderzoeken nogal varieert, proberen alle de validiteit aan te tonen door de resultaten van zelfevaluatie te vergelijken

\footnotetext{
* Deze bijdrage is gebaseerd op de tekst van een artikel dat later dit jaar wordt gepubliceerd in het Engelstalige tijdschrift Advances in Health Sciences Education. De huidige publicatie in het Tijdschrift voor Medisch Onderwijs vindt plaats met toestemming van Springer Science and Business Media.
} 
met die van beoordelingen door experts of objectieve toetsing. De resultaten leveren weinig bewijs voor de validiteit van zelfevaluatie in vergelijking met externe beoordelingen. ${ }^{48-25}$ Zelfs herhaalde persoonlijke feedback gebaseerd op objectief bepaalde kennis- en vaardighedenscores verbeterde de nauwkeurigheid niet. ${ }^{22}$ Op grond van deze bevindingen kunnen we concluderen dat zelfevaluatie van klinische competentie kennelijk meer zegt over hoe iemand haar of zijn competentie inschat (zelf ervaren competentie) $)^{25-27}$ dan over de feitelijke klinische competentie. ${ }^{2} 18$ 22-24

Van een medische opleiding mogen we verwachten dat het niet alleen de overdracht van kennis en vaardigheden ondersteunt, maar ook de mate waarin leerlingen zichzelf competent achten. Dit geldt zeker voor een vervolgopleiding, zoals de huisartsopleiding, die opleidt tot zelfstandige beroepsuitoefening. Bovendien biedt een vervolgopleiding een rijke klinische context (huisartspraktijk of ziekenhuis) in combinatie met speciale onderwijsprogramma's. Juist van deze combinatie valt te verwachten dat hij bijdraagt aan het eigen gevoel van competentie.

In het hier beschreven onderzoek zijn we deze veronderstelling nagegaan. We onderzochten de toename van zelf ervaren competentie in de huisartsopleiding. Omdat er weinig bekend is over welke factoren van invloed zijn op zelf ervaren competentie, zijn we ook nagegaan in hoeverre achtergrondvariabelen de toename ervan kunnen verklaren. We gingen dit na voor de variabelen 'leeftijd', 'geslacht', 'voorafgaande medische ervaring', 'de mate waarin iemand haar/zijn best heeft gedaan tijdens de opleiding' en 'de mate waarin iemand inzicht heeft gekregen in haar/zijn sterke en zwakke kanten van klinische competentie'. Hoewel er geen direct verband lijkt te bestaan tussen zelf ervaren en feitelijke klinische competen- tie, kunnen kennis en vaardigheden de groei van zelf ervaren competentie wel beïnvloeden. Daarom hebben we ook gekeken naar de relatie tussen de scores op kennistoetsen en de groei van zelf ervaren competentie.

\section{Methode}

\section{Procedure en deelnemers}

We vroegen alle huisartsen in opleiding (aios) die in september 1995 met de opleiding startten $(\mathrm{n}=191)$ om aan het begin en het einde van de opleiding een vragenlijst in te vullen, waarin hun zelf ervaren klinische competentie werd gemeten. Ook verzamelden we gegevens over de achtergrondvariabelen. We vergeleken de resultaten van beide metingen met elkaar en we analyseerden de relatieve bijdrage van de achtergrondvariabelen op de uitkomst.

\section{Context van het onderzoek}

Ons onderzoek betrof het curriculum van de driejarige huisartsopleiding, zoals dat tussen 1995 en 1998 vorm gegeven werd (zie box 1). ${ }^{28}$ Gedurende de drie jaar besteedden aios vier dagen per week aan leren in de praktijk en één dag aan georganiseerd onderwijs op een van de acht opleidingsinstituten. De opleiding bestond uit drie blokken van een jaar, te beginnen met een leerwerkperiode in de huisartspraktijk, gevolgd door leerwerkperiodes in ziekenhuizen, verpleeghuizen en GGZ-instellingen, om te eindigen met een leerwerkperiode in de huisartspraktijk. De inhoud van het programma was gebaseerd op het basistakenpakket van de huisarts en richtte zich op de verwerving van die kennis, vaardigheden en attitude die relevant zijn voor de huisartsgeneeskunde.

\section{Instrument}

We ontwikkelden een zelfevaluatie vragenlijst op basis van de leerdoelen van het 


\author{
Inhoud Basistakenpakket van de huisarts. \\ Structuur Drie blokken van gelijke duur: \\ Blok 1 Leerwerkperiode in een huisartspraktijk. \\ Blok 2 Leerwerkperiodes in een ziekenhuis, \\ verpleeghuis en GGZ-instelling. \\ Blok 3 Leerwerkperiode in een huisartspraktijk.
}

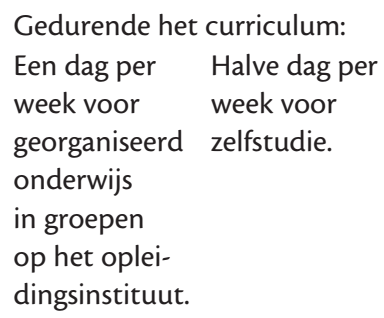

Gedurende het curriculum:

Een dag per Halve dag per week voor week voor georganiseerd zelfstudie. onderwijs in groepen op het opleidingsinstituut.

Leerdoelen Blok 1 Verwerving van kennis, vaardigheden en attitude met de nadruk op veel voorkomende, gewone problemen.

Blok 2 Verwerving van kennis, vaardigheden en attitude die niet in de huisartspraktijk geleerd kunnen worden.

Blok 3 Integratie van de nieuwe kennis, vaardigheden en attitude met de nadruk op complexe problemen.

onderwijsprogramma: de verwerving van kennis en vaardigheden. Voor vaardigheden werd een onderscheid gemaakt tussen klinische vaardigheden en consultvoeringsvaardigheden.

Het domein 'kennis' werd vertegenwoordigd door de International Classification of Primary Care (ICPC). ${ }^{29}$ Van de 17 categorieën van de ICPC vroegen we de aios hun kennisniveau in te schatten op een 3puntsschaal (geen, enige, veel kennis).

Het domein 'klinische vaardigheden' werd zowel vertegenwoordigd door de ICPC als door een lijst van specifieke patiëntengroepen (kinderen, ouderen, beroepsbevolking, migranten, geweldsslachtoffers, verslaafden, patiënten met acute en chronische aandoeningen, en stervenden). We vroegen de aios hun vaardighedenniveau in te schatten op een 4puntsschaal (nauwelijks enige, matige, redelijke, goede beheersing).

Het domein 'consultvoeringsvaardigheden' werd vertegenwoordigd door een lijst van vijf items die de belangrijkste aspecten van het huisartsgeneeskundig hulpverleningsproces samenvatten (de systematiek van het consult, het diagnostisch en therapeutisch beleid, de instand- houding van een goede arts-patiëntrelatie, de bewaking van de continuïteit in de zorg en preventie). We vroegen de aios hun vaardighedenniveau in te schatten op een 4-puntsschaal (nauwelijks enige, matige, redelijke, goede beheersing).

De betrouwbaarheid (Cronbach's alpha) van respectievelijk de begin- en eindmeting was $0.8 / 0.9$ voor kennis, $0.8 / 0.9$ voor klinische vaardigheden en $0.7 / 0.7$ voor consultvoeringsvaardigheden. Deze betrouwbaarheden zijn voldoende, zeker waar het de interpretatie van groepsresultaten betreft zoals in dit onderzoek.

\section{Factoren die van invloed zijn op zelf erva-} ren klinische competentie (achtergrondvariabelen)

Op basis van de literatuur en gezond verstand verwachtten we dat de volgende factoren van invloed zijn op de groei van zelfervaren competentie.

We kozen leeftijd en voorafgaande medische ervaring, omdat zij (levens)ervaring vertegenwoordigen. Dat kan leiden tot een toename van zelfvertrouwen. Bleys et al. vonden dat voorafgaande medische ervaring een positief effect had op de zelfervaren groei van sommige aspecten van 
competentie tijdens een kort onderwijsprogramma. ${ }^{30}$ We definieerden voorafgaande medische ervaring als 'de tijd tussen het behalen van het artsexamen en de start van de huisartsopleiding'.

We verwachtten dat geslacht van invloed is op de wijze waarop iemand zichzelf inschat. Vrouwen zijn mogelijk kritischer voor zichzelf dan mannen en dat kan resulteren in minder zelfervaren competentie. ${ }^{31}$

Hoewel de inhoud, structuur en leerdoelen van het onderwijsprogramma in grote lijnen gelijk waren voor de acht opleidingsinstituten, bestond er variatie in de manier waarop het onderwijs werd vorm gegeven. Dit kan hebben geleid tot verschillen in zelf ervaren competentie bij de aios.

Uit onderzoek blijkt dat hoe meer iemand zijn best doet voor haar/zijn opleiding, des te hoger diegene haar/zijn klinische competentie inschat. ${ }^{13}$ Daarom hebben we de aios aan het einde van hun opleiding gevraagd aan te geven hoe goed ze hun best hebben gedaan (we hebben dit moeite genoemd). Bovendien hebben we ze gevraagd in welke mate docenten hen gedurende de opleiding inzicht hebben gegeven in hun zwakke en sterke kanten. Wij verwachtten dat dit inzicht zou leiden tot een grotere toename van zelf ervaren competentie.

Tenslotte hebben we, om de invloed van kennis en klinische vaardigheden op de groei van zelf ervaren competentie te onderzoeken, de begin- en eindscores op de kennistoetsen van de deelnemende aios gebruikt als achtergrondvariabelen. In de huisartsopleiding worden geregeld kennistoetsen afgenomen. Deze toetsen hebben het format van een voortgangstoets, dat wil zeggen dat voor elke toets gepoogd wordt de cognitieve eindtermen van het curriculum weer te geven. Ze zijn samengesteld volgens een blauwdruk die gebaseerd is op de ICPC. Om de huisartsgeneeskundige relevantie te bevorderen, zijn de vragen ingebed in vignetjes die authentieke praktijksituaties beschrijven. Er zijn twee soorten toetsen: de Landelijke Huisartsgeneeskundige Kennistoets (LHK), waarin algemene kennis wordt getoetst, en de Kennis Over Vaardighedentoets (KOV). 32-33 Omdat onderzoek heeft aangetoond dat de KOV prestaties op een stationstoets kan voorspellen, achtten wij de KOV geschikt om de invloed van klinische vaardigheden te onderzoeken. ${ }^{33}$

\section{Analyse}

Voor ieder meetmoment berekenden we de gemiddelde scores en standaarddeviaties voor de domeinen 'zelf ervaren kennis', 'zelf ervaren klinische vaardigheden' en 'zelf ervaren consultvoeringsvaardigheden'. We testten verschillen op statistische significantie met een gepaarde t-test.

Om de relatie tussen de groei van zelf ervaren klinische competentie en de achtergrondvariabelen te exploreren, berekenden we de partiële correlaties tussen deze variabelen en de eindscore op de zelfevaluatielijst (post-test), gecorrigeerd voor de beginscore op deze lijst (pre-test). Hiermee introduceerden we 'groei' als de feitelijke afhankelijke variabele. ${ }^{34}$ Voor de invloed van het opleidingsinstituut op de groei gebruikten we het General Linear Model (GML). ${ }^{35}$ Tot slot voerden we een multiple regressieanalyse uit om te onderzoeken of een combinatie van achtergrondvariabelen de groei van zelf ervaren competentie beter kan verklaren. We hebben in deze regressieanalyse ook de groei van objectief gemeten kennis en vaardigheden tijdens de opleiding ingevoerd door de kennistoetsscores aan het einde van de opleiding te corrigeren voor die aan het begin.

\section{Resultaten}

\section{Deelnemers}

Van de 191 haio's vulden 127 aios beide zelfevaluatielijsten in. Deze resultaten 
werden gebruikt ten behoeve van het onderzoek. De deelnemers verschilden niet significant van de niet-deelnemers wat betreft leeftijd, wachttijd en beginniveau van algemene kennis en kennis over vaardigheden (t-test; $\mathrm{p}>0.05$ ). Het percentage mannelijke aios was iets hoger voor de deelnemers dan voor de niet-deelnemers (47\% versus $41 \%$ ). Zeven van de acht opleidingsinstituten waren vertegenwoordigd met een minimum van 4 en een maximum van 34 aios.

\section{Zelfevaluatielijst}

In tabel 1 zijn per domein de resultaten van zelf ervaren klinische competentie weergegeven. Zelf ervaren kennis nam toe van 'enige kennis' naar een niveau tussen 'enige kennis' en 'veel kennis'. Voor zelf ervaren klinische vaardigheden startten de aios met een niveau tussen

'matige beheersing' en 'redelijke beheersing' om te eindigen met een meer dan 'redelijke beheersing'. Zelf ervaren consultvoeringsvaardigheden toonden de meeste toename: van 'matige beheersing' naar een niveau tussen 'redelijke beheersing' en 'goede beheersing'. Alle verschillen waren statistisch significant.

\section{Achtergrondvariabelen}

De achtergrondvariabelen waren normaal verdeeld. Tabel 2 toont de partiële correlaties, die het verband weergeven tussen de variabelen 'leeftijd', 'voorafgaande medische ervaring', 'geslacht', 'moeite', 'inzicht en kennistoetsscores' en de groei van zelf ervaren kennis, klinische vaardigheden en consultvoeringsvaardigheden. Geen van de achtergrondvariabelen toonde een verband met groei van zelf ervaren competentie. Ook het opleidingsinstituut had er geen invloed op.

De regressieanalyse leverde geen bewijs voor een significante bijdrage van de achtergrondvariabelen aan de groei van respectievelijk zelfervaren kennis, klinische en consultvoeringsvaardigheden. Voor de drie domeinen werd slechts $25 \%$ van de variantie verklaard door alle variabelen gezamenlijk.

\section{Discussie en conclusie}

De resultaten van dit onderzoek laten zien dat een driejarige vervolgopleiding tot huisarts, die bestaat uit leren in een klinische omgeving én programmatisch onderwijs, bijdraagt aan het eigen gevoel van competentie. Deze bijdrage is zodanig dat de aios zich aan het einde van de opleiding voldoende competent achten ten aanzien van hun kennis, klinische vaardigheden en consultvoeringsvaardigheden. Met betrekking tot deze drie domeinen vonden wij een wat verschillend 'groeipatroon'. Aan het begin van de opleiding beschouwden de aios zich ongeveer even competent in kennis als in klinische vaardigheden,

Tabel 1 Gemiddelde scores en standaarddeviaties (SD) op de zelfevaluatie vragenlijst voor de domeinen 'kennis',' klinische vaardigheden' en'consultvoeringsvaardigheden'.

\begin{tabular}{lcccc}
\hline & & Begin opleiding & Einde opleiding & \\
\cline { 3 - 4 } Domein & $\mathrm{N}$ & Gemiddelde (SD) & Gemiddelde (SD) & Significantie* \\
\hline $\begin{array}{l}\text { Kennis (3-puntsschaal) } \\
\text { Klinische vaardigheden }\end{array}$ & 123 & $2.0(0.2)$ & $2.5(0.3)$ & $\mathrm{p}<0.001$ \\
$\begin{array}{l}\text { (4-puntsschaal)** } \\
\begin{array}{l}\text { Consultvoeringsvaardigheden } \\
(\text { (4-puntsschaal)** }\end{array}\end{array}$ & 125 & $2.5(0.4)$ & $3.2(0.3)$ & $\mathrm{p}<0.001$ \\
\hline
\end{tabular}

${ }^{*}$ t-test; +1 = geen, $2=$ enige, $3=$ veel; ${ }^{* *} 1$ = nauwelijks enige; $2=$ matig; 3 = redelijk; $4=$ goed. 
Tabel 2 Partiële correlaties tussen resp. de groei van zelf ervaren kennis, klinische vaardigheden en consultvoeringsvaardigheden, en de achtergrondvariabelen die er mogelijk op van invloed zijn.

\begin{tabular}{|c|c|c|c|c|c|c|}
\hline \multirow[b]{2}{*}{ Achtergrondvariabelen } & \multicolumn{2}{|c|}{ Zelf ervaren kennis } & \multicolumn{2}{|c|}{$\begin{array}{l}\text { Zelf ervaren klinische } \\
\text { vaardigheden }\end{array}$} & \multicolumn{2}{|c|}{$\begin{array}{l}\text { Zelf ervaren consult- } \\
\text { voeringsvaardigheden }\end{array}$} \\
\hline & Corr. & $\mathrm{N}$ & Corr. & $\mathrm{N}$ & Corr. & $\mathrm{N}$ \\
\hline Leeftijd & -0.07 & 118 & 0.02 & 120 & -0.07 & 122 \\
\hline $\begin{array}{l}\text { Voorafgaande medische } \\
\text { ervaring }\end{array}$ & -0.07 & 120 & 0.01 & 122 & -0.06 & 124 \\
\hline Geslacht & -0.09 & 120 & 0.12 & 122 & -0.03 & 124 \\
\hline Moeite & -0.10 & 119 & -0.16 & 121 & -0.10 & 123 \\
\hline Inzicht & 0.04 & 120 & 0.04 & 122 & 0.05 & 124 \\
\hline LHK* beginmeting & -0.03 & 120 & -0.0 & 122 & -0.04 & 124 \\
\hline LHK* eindmeting & 0.19 & 107 & 0.10 & 109 & 0.1 & 111 \\
\hline $\mathrm{KOV}+$ beginmeting & 0.01 & 120 & 0.07 & 122 & -0.05 & 124 \\
\hline KOV† eindmeting & 0.07 & 85 & -0.07 & 87 & -0.1 & 89 \\
\hline
\end{tabular}

* Landelijke Huisartsgeneeskundige Kennistoets; † Kennis Over Vaardighedentoets.

terwijl ze zich minder competent voelden in consultvoering. Aan het einde van de opleiding was dit precies het tegenovergestelde. Kennelijk versterkt het curriculum het eigen gevoel van competentie in consultvoering meer dan dat van kennis en klinische vaardigheden.

Onze tweede onderzoeksvraag was of er achtergrondvariabelen zijn die de groei van zelf ervaren competentie kunnen verklaren. Voor de door ons gekozen variabelen (leeftijd, voorafgaande medische ervaring, opleidingsinstituut, geslacht, moeite, inzicht en kennistoetsscores) leverden de resultaten van dit onderzoek geen beslissend bewijs.

Het algemene resultaat van het eerste deel van ons onderzoek was in overeenstemming met wat we verwachtten: een medische vervolgopleiding draagt bij aan het eigen gevoel van klinische competentie. Het verschil in groei tussen de drie onderscheiden domeinen was onverwacht, maar consistent met het tweede deel van het onderzoek dat laat zien dat een toename van zelf ervaren klinische competentie niet verklaard kan worden door een toename van objectief gemeten klinische competentie. We hebben namelijk in drie andere studies de groei van objectief gemeten kennis, klinische vaardigheden en communicatievaardigheden onderzocht bij hetzelfde cohort aios. ${ }^{32}$ 3637 In die studies toonden we een toename van kennis en klinische vaardigheden aan en geen verbetering van communicatievaardigheden. Dus ook hier zien we een verschil tussen objectief gemeten en zelf ingeschatte groei. Uit de literatuur weten we dat er geen directe relatie lijkt te zijn tussen zelf ingeschatte en objectief gemeten klinische competentie. ${ }^{25-27}$ Ons onderzoek toont aan dat ook de groei van beide gedurende de opleiding geen verband met elkaar lijkt te hebben. Deze bevinding bevestigt de veronderstelling dat zelfinschatting van klinische competentie iets anders meet dan objectief vastgestelde klinische competentie. Kennelijk versterken andere factoren dan 'echte' competentie het eigen gevoel van competentie. Helaas wordt uit dit onderzoek niet duidelijk welke factoren dit zijn. Ook de andere door ons onderzochte achtergrondvariabelen bieden geen verklaring voor de toename van zelf ervaren competentie. Het is, bijvoorbeeld, 
opvallend dat de mate waarin iemand tijdens de opleiding inzicht krijgt in haar/ zijn sterke en zwakke kanten van klinische competentie geen invloed lijkt te hebben op haar/zijn eigen gevoel van competentie.

Onze bevindingen vergroten de onduidelijkheid ten aanzien van wat we meten met zelfevaluatie. In de literatuur worden verschillende aspecten genoemd die verwijzen naar het concept erachter (zelfvertrouwen, 2538 potentiële of ideale prestatie en moeite, 1315 zelfbescherming, ${ }^{9}$ handhaving van zelfrespect, ${ }^{15}$ niet-cognitieve competentie, ${ }^{11}$ zelfattributies, ${ }^{4}$ en meer overeenkomend met karaktereigenschappen dan met probleemoplossend gedrag ${ }^{39}$ ). Hoewel deze interpretaties aannemelijk lijken, hebben we geen publicatie gevonden waarin het theoretisch concept van zelfevaluatie in het medisch onderwijs diepgaand is behandeld. Omdat zelfevaluatie op grote schaal wordt toegepast in het medisch onderwijs, en zelfs meer betekenis krijgt in competentiegerichte opleidingen, en het belang ervan voor zelfgestuurd leren en professionele autonomie algemeen onderschreven wordt, ${ }^{3-8}$ is dringend behoefte aan een dergelijk concept. Recent kwamen Eva en Regehr tot dezelfde conclusie na een grondige beschouwing van de functie van zelfevaluatie voor een professional in de gezondheidszorg en een review van de psychologische literatuur gericht op zelfevaluatie. 40

Concluderend hebben we in dit onderzoek aangetoond dat tijdens een driejarige vervolgopleiding tot huisarts het eigen gevoel van competentie in kennis, klinische vaardigheden en consultvoeringsvaardigheden toeneemt. Echter, we weten nog steeds niet hoe deze toename te verklaren is. Meer studie naar het theoretisch concept van zelfevaluatie en naar de factoren die bijdragen aan het eigen gevoel van competentie is nodig.

\section{Literatuur}

1. Boud D. The role of self-assessment in student grading. Assessment and Evaluation in Higher Education 1989;14:20-30.

2. Purdy M. The problem of self-assessment in nurse education. Nurse Education Today 1997;17:1359.

3. Miller GE. Continuous assessment. Med Educ 1976;10:81-6.

4. Gordon MJ. A review of the validity and accuracy of self-assessments in health professions training. Acad Med 1991;66:762-9.

5. Irvine D. The performance of doctors. I: Professionalism and self regulation in a changing world. BMJ 1997;314:1540-2.

6. Oermann MH. Professional reflection: have you looked in the mirror lately? Orthopaedic Nursing 1998:22-6.

7. Mattheos N, Nattestad A, Falk-Nilsson, Attström R. The interactive examination: assessing students' self-assessment ability. Med Educ 2004;38:378-89.

8. Ward M, Gruppen L, Regehr G. Measuring selfassessment: current state of the art. Adv Health Sci Educ 2002; 7:63-80.

9. Harris MH, Schaubroeck J. A meta-analysis of self-supervisor, self-peer, and peer-supervisor ratings. Personnel Psychology 1988;41:43-62.

10. Stuart MR, Goldstein HS, Snope FC. Self-evaluation by residents in family medicine. J Fam Pract 1980;10:639-42.

11. Arnold L, Willoughby TL, Calkins EV. Self-evaluation in undergraduate medical education: a longitudinal perspective. J Med Educ 1985;60:21-8.

12. Rezler AG. Self-assessment in problem-based groups. Med Teach 1989;11:151-6.

13. Risucci DA, Tortolani AJ, Ward RJ. Ratings of surgical residents by self, supervisor and peers. Surg Gyn Obs 1989;169:519-26.

14. Donald JB, Thomson D. Evaluation of a computerized assessment package for general practitioner trainees. Br J Gen Pract 1993;43:115-8.

15. Woolliscroft JO, Ten Haken J, Smith J, Calhoun JG. Medical students' clinical self-assessments: comparisons with external measures of performance and the students' self-assessments of overall performance and effort. Acad Med 1993;68:285-94.

16. Harrington JP, Murnaghan JJ, Regehr G. Applying a relative ranking model to the self-assessment of extended performances. Adv Health Sci Educ 1997;2:17-25.

17. Tracey JM, Arroll B, Richmond DE, Barham PM. The validity of general practitioners' self assessment of knowledge: cross sectional study. BMJ 1997;315:1426-8. 
18. Johnson D, Cujec B. Comparison of self, nurse, and physician assessment of residents rotating through an intensive care unit. Crit Care Med 1998;26:1811-6.

19. Martin D, Regehr G, Hodges B, McNaughton N. Using videotaped benchmarks to improve the self-assessment ability of family practice residents. Acad Med 1998;73:1201-6.

19. Fox RA, Ingham Clark CL, Scotland AD, Dacre JE. A study of pre-registration house officers' clinical skills. Med Educ 2000;34:1007-12.

20. Friedlich M, MacRae H, Oandasan I, Tannenbaum D, Batty H, Reznick R, et al. Structured Assessment of Minor Surgical Skills (SAMSS) for family medicine residents. Acad Med 2001;76:1241-6.

21. Jansen JJM, Grol RPTM, Crebolder HFJM, Rethans JJ, van der Vleuten CPM. Failure of feedback to enhance self-assessment skills of general practitioners. Teach Learn Med 1998;10:145-51.

22. DiMatteo MR, DiNicola DD. Sources of assessment of physician performance: a study of comparative reliability and patterns of intercorrelation. Med Care 1981;19:829-39.

23. Calhoun JG, Ten Haken JD, Woolliscroft JO. Medical students' development of self- and peer-assessment skills: a longitudinal study. Teach Learn Med 1990;2:25-9.

24. Kegel-Flom P. Predicting supervisor, peer, and self ratings of intern performance. J Med Educ 1975;50:812-5.

25. Speechly M, Weston WW, Dickie GL, Orr V. Selfassessed competence: before and after residency. Can Fam Phys 1994;40:459-64.

26. Marel GM, Lyon PM, Field MJ, Barnsley L, Hibbert E, Parise A. Clinical skills in early postgraduate medical training: patterns of acquisition of confidence and experience among junior doctors in a university teaching hospital. Med Educ 2000;34:1013-5.

27. Dubois V, Everwijn S, van Geldorp G, et al. The construction of a new curriculum of postgraduate training for general practice in the Netherlands. Utrecht: KNMG; 1987.

28. Lamberts H, Wood M, editors. ICPC. International Classification of Primary Care. Oxford: Oxford University Press; 1987.

29. Bleys FC, Gerritsma JGM, Netjes I. Skills development by medical students and the influence of prior experience: a study using evaluations by students and self-assessment. Med Educ 1986;20:234-9.

30. Coutts L, Rogers J. Student assessment and standardized patients - will the questions never end? Acad Med 1999;74(10 Suppl):S128-30.

31. Kramer AWM, Düsman H, Tan LHC, Jansen JJM, Grol RPTM, van der Vleuten CPM. Effect of extension of postgraduate training in general prac- tice on the acquisition of knowledge of trainees. Fam Practice 2003;20:207-12.

32. Kramer AWM, Zuithoff P, Düsman H, Jansen JJM, Tan LHC, Grol RPTM, et al. Predictive validity of a written knowledge test of skills in postgraduate training for general practice. Med Educ 2002;36:812-9.

33. Cronbach LJ. How we should measure 'change' - or should we? Psychol Bull 1970;74:68-80.

34. SPSS Advanced Statistics 7.5. Chigago: SPSS Inc; 1997. p. 89-130.

35. Kramer AWM, Jansen JJM, Düsman H, Tan LHC, van der Vleuten CPM, RPTM Grol. Acquisition of clinical skills in postgraduate training for general practice. Br J Gen Pract 2003;53:677-82.

36. Kramer AWM, Düsman H, Tan LHC, Jansen JJM, Grol RPTM, van der Vleuten CPM. Acquisition of communication skills in postgraduate training for general practice. Med Educ 2004;38:158-67.

37. Swanwick T. Informal learning in postgraduate medical education: from cognitivism to 'culturism'. Med Educ 2005;39:859-65.

38. Fitzgerald JT, Gruppen LD, White CB. The influence of task formats on the accuracy of medical students' self-assessments. Acad Med 2000;75:73741.

39. Eva KW, Regehr G. Self-assessment in the health professions: a reformulation and research agenda. Acad Med 2005;80(10Suppl):S46-54.

\section{De auteurs:}

Dr. A.W.M. Kramer, huisarts, ten tijde van het onderzoek SVUH, Utrecht, thans Voortgezette opleiding tot huisarts, UMC St Radboud, Nijmegen.

Drs. P. Zuithoff, ten tijde van het onderzoek SVUH, Utrecht, thans afdeling Huisartsgeneeskunde, UMCU, Utrecht.

Dr. J.J.M. Jansen, huisarts, SVUH, Utrecht.

Dr. L.H.C. Tan, ten tijde van het onderzoek SVUH, Utrecht, thans met pensioen.

Prof. dr. R.P.T.M. Grol, afdeling Quality of Care Research, UMC St Radboud, Nijmegen.

Prof. dr. C.P.M. van der Vleuten, afdeling Onderwijsontwikkeling en -onderzoek, Universteit van Maastricht.

\section{Correspondentieadres:}

Dr. A.W.M. Kramer, Voha, UMC St Radboud, Postbus 9101, 6500 HB Nijmegen, tel.: 024-3618827/3615300, A.Kramer@voha.umcn.nl.

Belangenconflict: Anneke Kramer was ten tijde van het onderzoek werkzaam bij het landelijk bureau Toetsing, Evaluatie en Onderzoek van onderwijs van de huisartsopleiding.

Financiële ondersteuning: het onderzoek is financieel ondersteund door de Stichting Beroepsopleiding Huisarts $(S B D H)$. 


\section{Summary}

Introduction: Aim of the study was to examine the increase in self-perceived clinical competence during a three-year postgraduate training in general practice and to explore the relation between the growth of self-perceived competence and several background variables.

Method: We asked the trainees at the start and at the end of their postgraduate training to complete a questionnaire, which assessed their self-perceived knowledge, clinical skills and consultations skills. We collected information about potentially influencing background variables. Amongst these were variables such as: age, gender, prior medical experience, the effort someone has spent upon her/his education, insight in weak and strong areas of clinical competence and knowledge and skills levels.

Results: 127 out of 190 trainees completed both questionnaires. We found statistically significant growth of self-perceived clinical competence. Self-perceived consultation skills increased more than self-perceived knowledge and clinical skills. The afore mentioned background variables did not relate in any way with the growth of self-perceived clinical competence.

Discussion: This study shows that a three-year postgraduate training in general practice enhances self-perceived clinical competence. However, we still do not know how to explain this improvement. Further study into the theoretical concept of self-assessment in medical education and into the factors contributing to the feeling of being competent, is required. This becomes even more prominent in self-directed, competency-based curricula. (Kramer AWM, Zuithoff $P$, Jansen JJM, Tan LHC, Grol RPTM, Vleuten CPM van der. Growth of self-perceived clinical competence in postgraduate training for general practice and its relation to potentially influencing factors. Dutch Journal of Medical Education 2006;25(3):134-142.) 